\title{
Cúpulas de barro, de piedra y de barro y piedra en las construcciones auxiliares de la arquitectura popular del centro de Castilla y León
}

\author{
Mud dome, stone dome and mud and stone dome in the rural buildings \\ of vernacular architecture in center of Castilla y León (Spain)
}

\author{
O. Abril Revuelta ${ }^{(*)}$, F. Lasheras Merino ${ }^{(*)}$
}

RESUMEN

En el centro de Castilla y León todavía existen algunos ejemplos de antiguas construcciones rurales vinculadas a las actividades económicas del mundo agrario. Conocidas como chozos y casetas, se cubrieron con soluciones cupuliformes empleándose los materiales que más a mano se tenían, siendo el barro y la piedra los más comunes. Las técnicas constructivas tradicionales en ambos elementos generaron un abanico tipológico singular, poco común en el resto de la península y digno de estudio. Gracias a un extenso trabajo de campo se han identificado, inventariado y clasificado una amplia variedad de tipos constructivos cupuliformes, que se han contrastado con fuentes documentales, ampliando significativamente la información publicada que se tenía de ellas, especialmente de su variedad y proceso constructivo. Esta investigación pretende proporcionar herramientas para valorar y recuperar un conocimiento constructivo que ya está olvidado, resaltando su riqueza arquitectónica, para fomentar su conservación e incluso la recuperación en algunos casos.

Palabras clave: adobe; arquitectura vernácula; bóveda; chozo; Montes Torozos; patrimonio rural; piedra; Tierra de Campos.

\section{ABSTRACT}

In the center of Castilla y León there are few examples of old rural buildings linked to economic activities that have developed in the agrarian field. These are known chozos and casetas, and they have been built with dome-shaped solutions using autochthon materials: mud and stone. The influence of traditional techniques of both elements has generated a singular typological rarely seen in the rest of the Iberian Peninsula. Different types of domes have been analyzed in situ. And they have been contrasted by documentary sources and it has significantly expanded the information published of them, especially about their typological variety and their construction process. This research aims to provide tools to restore a constructive knowledge that is forgotten in place, to value its architectural wealth, which can encourage their rehabilitation.

Keywords: adobe; coberlled dome; rural heritage; stone; Tierra de Campos; Torozos; vault; vernacular architecture.

(*) Departamento de Construcción y Tecnología Arquitectónicas, Universidad Politécnica de Madrid (UPM), Grupo de Investigación de Análisis e Intervención en Patrimonio Arquitectónico (AIPA), Madrid (España).

Persona de contacto/Corresponding author: oscarq.ar@gmail.com (O. Abril Revuelta) ORCID: http://orcid.org/oooo-0oo1-6442-6906 (O. Abril Revuelta); http://orcid.org/oooo-0002-1252-5360 (F. Lasheras Merino)

Cómo citar este artículo/Citation: Abril Revuelta, O., Lasheras Merino, F. (2017). Cúpulas de barro, de piedra y de barro y piedra en las construcciones auxiliares de la arquitectura popular del centro de Castilla y León. Informes de la Construcción, 69(546): e198, doi: http://dx.doi.org/10.3989/id54749.

Copyright: (C) 2017 CSIC. Licencia / License: Salvo indicación contraria, todos los contenidos de la edición electrónica de Informes de la Construcción se distribuyen bajo una licencia de uso y distribución Creative Commons Attribution License (CC BY) Spain 3.o. 


\section{INTRODUCCIÓN. SISTEMAS ABOVEDADOS EN EL CENTRO CASTELLANO}

El presente trabajo forma parte de una amplia investigación iniciada en 2013, desarrollada dentro del grupo de Investigación AIPA de la UPM, y de la que ya se han publicado otros resultados parciales en simposios, congresos y revistas relacionadas con el patrimonio vernáculo. En ella se han localizado e inventariado más de 200 edificaciones en 66 municipios en las provincias de León, Palencia, Valladolid y Zamora. En el presente artículo nos centramos en las soluciones abovedadas ejecutadas para las techumbres de los refugios agropecuarios, levantadas tan sólo con los dos principales materiales autóctonos del centro castellano: barro y piedra.

Estas construcciones auxiliares de la arquitectura popular se utilizaban para guardar aperos de labranza y, ocasionalmente, para pernoctar como casetas de vigilancia o para protegerse de las inclemencias del tiempo en la actividad pastoril; en la zona del ámbito de estudio se conocen como chozos o casetas. Se construyeron con técnicas rudimentarias de albañilería, pero no por eso exentas de ingenio. Su variedad y personalidad las hace distinguirse de otras peninsulares con las que comparten aparentes similitudes constructivas.

Sobre ellas destaca en la mayoría de casos su figura cupuliforme, solución que lleva realizándose desde tiempos inmemoriales por todo tipo de culturas. Muchas de estas cúpulas han desaparecido, y las que aún mantienen su maltrecho estado están próximas a extinguirse. La transformación del campo de los últimos 60 años ha industrializado la explotación agrícola y ganadera, y ha cambiado por completo la arquitectura vinculada al mundo rural. Por otra parte, el conocimiento constructivo para edificar con los materiales tradicionales también está a punto de perderse, pues desde hace mucho tiempo han dejado de utilizarse las técnicas de una arquitectura popular cuya sabiduría se ha transmitido tradicionalmente de manera oral y visual, en contraposición de la arquitectura culta que se ha difundido de manera escrita y gráfica (1).

Es por ello que, a partir de estos dos grandes problemas, encontramos una oportunidad para documentar los procesos constructivos empleados para la ejecución de cúpulas y desvelar alguna de las hipótesis planteadas en cuanto a los métodos tradicionales empleados y a la naturaleza material de la propia techumbre, puesto que la aparición de sistemas mixtos poco empleados y documentados podrían suponer una evolución por parte de los maestros locales a la hora de mejorar la solución abovedada.

\section{MÉTODO DE TRABAJO}

La primera fase en el estudio aborda la documentación específica de las techumbres de estas edificaciones a través de los trabajos de autores que se han interesado por sus soluciones abovedadas, no sólo en la zona de estudio, sino por toda la península u otros países (2). De esta manera es posible destacar entre todos los ejemplos vistos a través de la bibliografía revisada diferentes conceptos que inciden en su construcción, como el sistema de colocación de las piezas, los materiales utilizados, la planta del muro soporte, los sistemas de arranque, el tipo de coronación, los revestimientos, etc.

Las inspecciones in situ son fundamentales para recoger los datos más precisos de todos los elementos que se han podido reconocer en el área de estudio. En total han sido 202 techumbres abovedadas analizadas y clasificadas según conceptos condicionantes en su desarrollo arquitectónico.

Como apoyo fundamental a la investigación se ha procedido a la reconstrucción de una cúpula de adobes en uno de los casos vistos, que estaba en estado ruinoso, suponiendo ésta una obra completamente experimental ${ }^{1} \mathrm{y}$ beneficiosa para resolver muchas de las cuestiones proyectadas.

\section{ESTADO DE LA CUESTIÓN}

El corazón de la Vieja Castilla ha sido fuente de inspiración para muchos autores, incluso por parte de los grandes investigadores de la arquitectura tradicional, como Carlos Flores (3) y Luis Feduchi (4), que han dedicado capítulos para la Meseta Norte o Septentrional en sus obras de marco nacional. Sus trabajos y las de otros interesados en la región castellana normalmente han centrado sus estudios en la vivienda popular, realizando un análisis tipológico de los elementos residenciales, y también han examinado los principales materiales y técnicas constructivas tradicionales empleadas (5). Las construcciones auxiliares de esta región han sido tan sólo referenciadas en subcapítulos sin entrar demasiado en su proceso constructivo, salvo para indicar que las cúpulas que techaban estos cobijos eran desarrolladas por el sistema de aproximación de hiladas o también llamada cúpula falsa (6).

En una visión completa del mapa peninsular cabe destacar el interesante esfuerzo realizado por Vegas, Mileto y Cristini (7), desde la Universidad Politécnica de Valencia, por ubicar el tipo de cúpulas de vuelos sucesivos (corbelled dome) de esta arquitectura vernácula según el material, destacando la piedra como material dominante, exceptuando la región de Tierra de Campos dominada por la arcilla (Figura 1).

No obstante, uno de los más preocupados en el conocimiento constructivo de estas bóvedas es Carlos Carricajo, quien advirtió de la transición entre el páramo y la llanura en la provincia de Valladolid con cúpulas mixturadas, combinando adobes y piedras. También diferenciaba las levantadas como cúpulas escalonadas, con piezas siempre horizontales, de las auténticas, donde eran inclinadas al centro de la bóveda (8). $\mathrm{Al}$ margen de este autor y de ciertas menciones en alguna publicación más sobre algún caso de la región, no existe un estudio pormenorizado que sea capaz de documentar y justificar detalladamente el empleo de las distintas soluciones abovedas detectadas en el lugar, ni tampoco de describir de una manera puntualizada el proceso completo de su ejecución, ni el tamaño de las piezas, ni las técnicas empleadas para su equilibrio estructural, etc. No obstante, serán referenciados en cada análisis aquellos cuyos trabajos han podido contribuir al entendimiento y justificación de los planteamientos propuestos para este artículo.

\footnotetext{
${ }^{1}$ Desarrollada como continuación del Curso de Extensión Universitaria de la UAH El paisaje de Urueña. Taller del barro, organizado por el Ayuntamiento de Urueña, Fundación Joaquín Díaz, Diputación de Valladolid y Universidad de Alcalá de Henares, 14-16 de abril de 2016 en Urueña (Valladolid).
} 
Provinces with presence of adobe corbelling domes

Provinces with huge presence of stone corbelling domes

Provinces with medium presence of stone corbelling domes

Provinces with few presence of stone corbelling domes

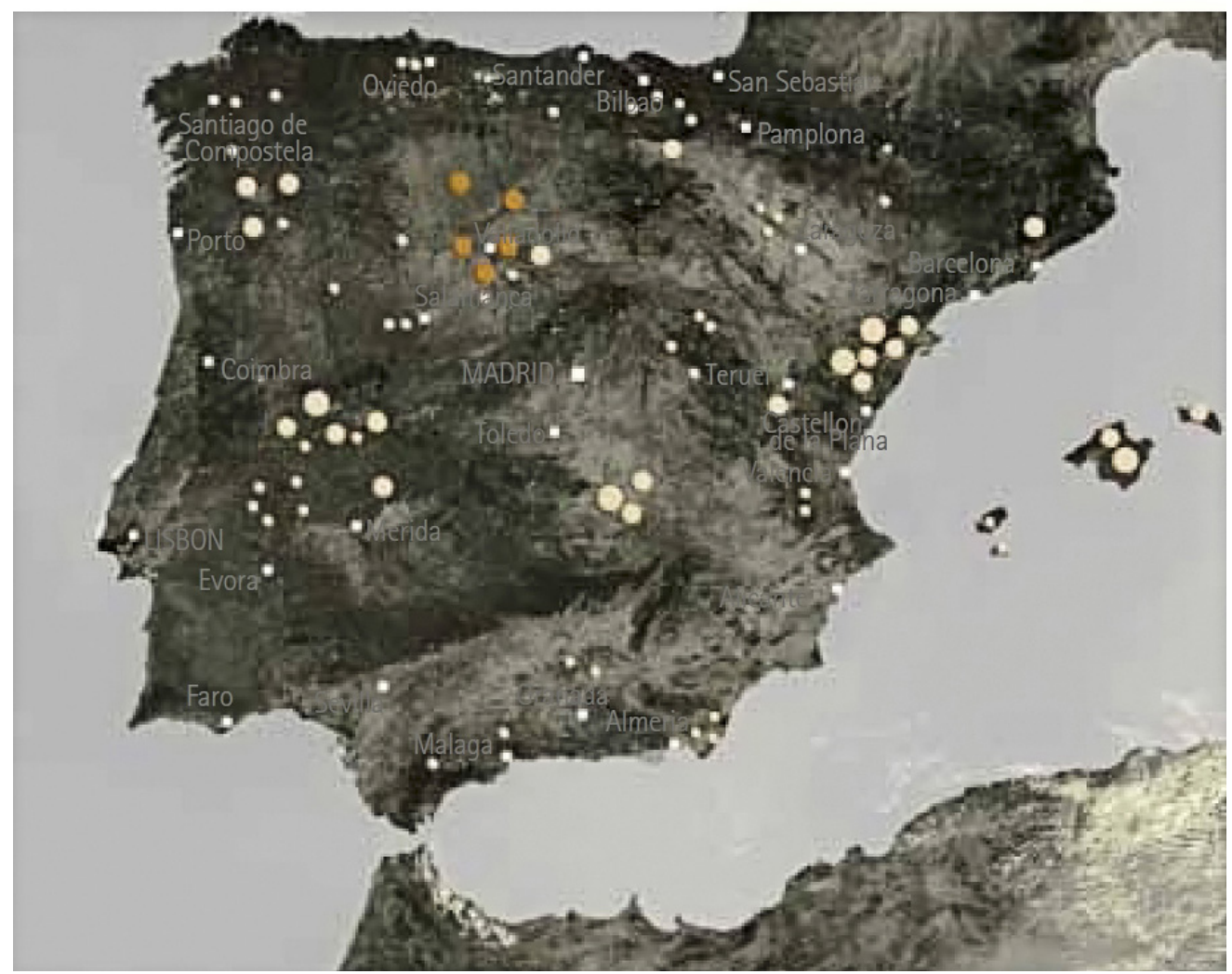

Figura 1. Mapa de la Península Ibérica. Tipos de cúpula en función del material en la arquitectura popular [F. Vegas, C. Mileto, y V. Cristini (7)].

\section{TRABAJO DE CAMPO. ANÁLISIS Y RESULTADOS}

\subsection{Materiales geológicos: piedra y barro}

Sabemos por el geógrafo Justo González Garrido (9) que desde siglos ha existido una gran dificultad de obtener madera en la zona de estudio, tanto por la escasez de masa arbórea en los terrenos agrícolas de la extensa región de Tierra de Campos como por la deforestación sufrida durante siglos en las zonas boscosas en algunos de los páramos como el de los Montes Torozos (10). De esta manera no es de extrañar que la solución abovedada se haya impuesto para techar los refugios teniendo en cuenta que lo que se disponía para ello era principalmente arcilla y caliza, según se comprueba en el mapa geológico (Figura 2).

Sobre este plano se señala en color blanco la zona de terreno rico en piedra caliza, principalmente correspondiente a la comarca de los Montes Torozos. El litoral azulado que lo bordea son áreas ricas en limos y margas. El resto de la zona en tonos amarillentos y marrones lo compone la matriz arcillosa en diferentes niveles de saturación de óxido de hierro y es la que se corresponde con la región de Tierra de Campos (11).

\subsection{Técnicas para la construcción de las cúpulas}

Para formar las cúpulas se utilizan en la zona dos técnicas básicas ampliamente conocidas. La más extendida es el sistema de aproximación de hiladas o cúpula falsa: consiste en colocar las piezas escalonadamente y volándolas progresivamente en cada anillo hacia el eje vertical de la cúpula, manteniendo la horizontalidad de sus lechos. Su origen es muy antiguo, según algunos autores desde el Neolítico (12), y se han visto ejemplos protohistóricos como los Tholos micénicos. La otra técnica, que es una solución más común para la arquitectura culta, es la cúpula auténtica: se consigue mediante la inclinación progresiva de piezas hacia el centro de la bóveda en cada hilada, a modo de dovelas de arco, lo que produce por norma general una figura más rebajada. No obstante, en ningún caso, estos refugios agropecuarios renuncian al carácter ojival que beneficia la evacuación de aguas.

Puesto que nuestras cúpulas se levantaron necesariamente sin cimbra, pues su uso resultaba económicamente prohibitivo (13), el funcionamiento estructural de estos elementos se debe a la formación de anillos de compresión. Gracias a la particular manera de colocar las piezas de cada hilada, ésta será estable por sí misma una vez completada (14).

No obstante, a través del trabajo de campo se han descubierto varios casos donde combinan ambos sistemas. Estamos ante una variante híbrida, hasta el momento desconocida en la bibliografía revisada de la arquitectura tradicional, aunque sí puede ser una estrategia vista en algunas construcciones góticas, cuya figura se asemeja mucho. En esta tercera opción el procedimiento consiste en un escalonamiento de las piezas en las zonas inferiores y una inclinación de las mismas en la 


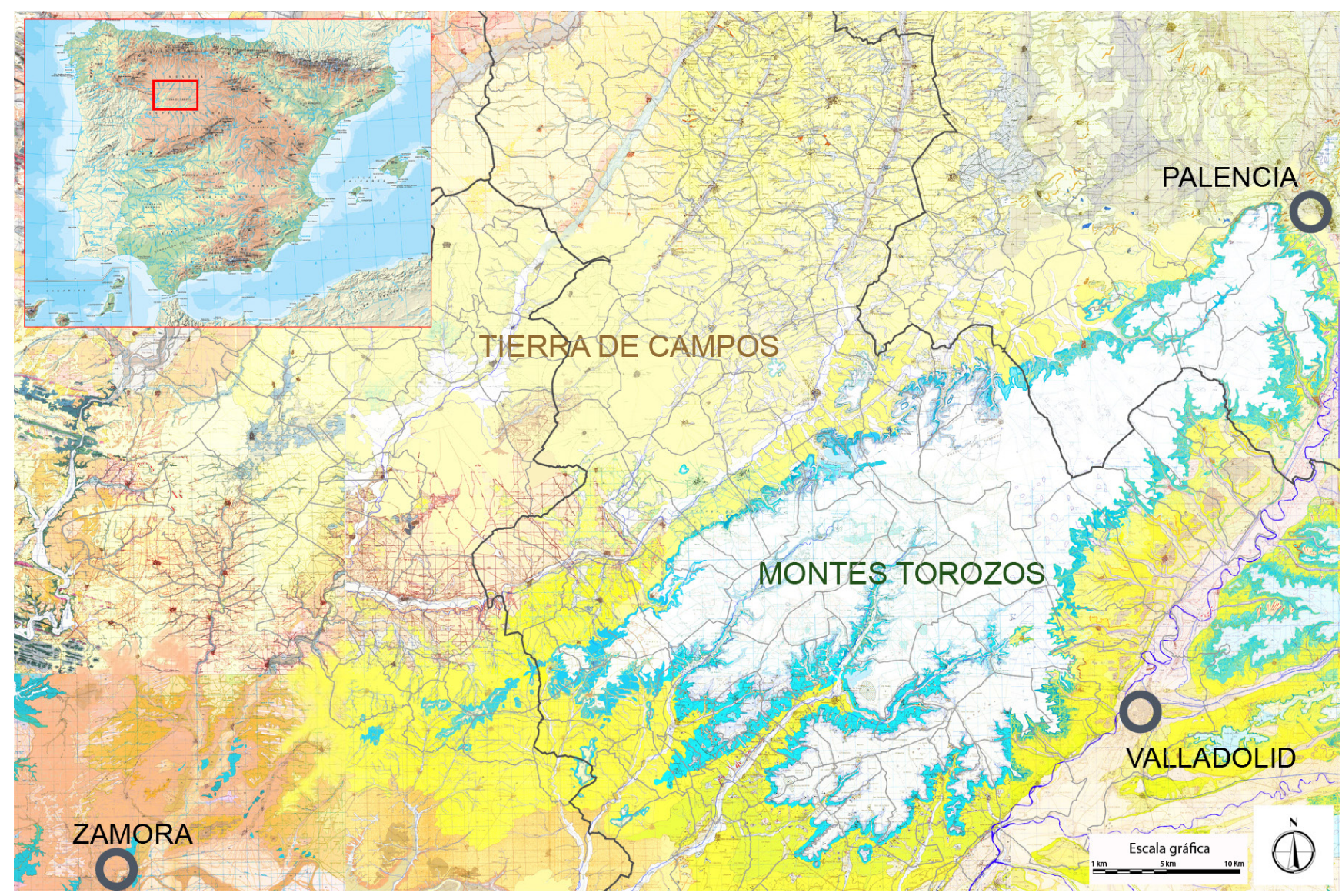

Figura 2. Mapa geológico de la zona estudiada [elaboración propia, a partir de planos del Instituto Geológico y Minero (11)].

coronación. Esta técnica permite lograr dos objetivos: elevar el espacio de la cúpula, especialmente cuando ésta nace desde el suelo, porque el sistema escalonado asciende con menor inclinación, y mejorar la ejecución en el cierre de la cúpula que en el sistema de aproximación de hiladas resulta más difícil (Figura 3).

La selección de un sistema u otro depende de varios factores; los más destacados se indican en la Tabla 1. El más determinante parece ser el material principal con el que se construye la cúpula. En el caso de las bóvedas de arcilla el elemento empleado es el adobe; gracias a la regularidad de su geometría y a su tamaño se convierte en un elemento idóneo para la ejecución de figuras de revolución. Además, es un elemento fácilmente ajustable a una forma especial, como una dovela, bien por el empleo de moldes especiales o mediante cortes. Es por ello que se ha visto tanto en cúpulas de aproximación de hiladas (41 casos), como en auténticas (30 ejemplos) y, por supuesto, en híbridas (9 casos).

Por su parte, las cúpulas pétreas han supuesto un enorme ejercicio de habilidad por sus ejecutores. Muchas de las que se han visto en la actualidad han sido reparadas recientemente utilizando para su recuperación argamasas (principalmente de cemento); sin embargo, la ejecución original de casi todas ellas se realiza con piedra en seco, eliminando el factor adherente del que sí disponían los adobes, asentadas con mortero de arcilla.

Además, los mampuestos que se colocaban eran sacados directamente del propio terreno, buscando los elementos que por tamaño y forma encajaran mejor. Raramente se emplea- ron piezas labradas, a no ser que se recogieran de alguna obra de arquitectura más señorial y fueran reutilizadas. De esta manera es posible justificar que el sistema dominante para las bóvedas de piedra es el de vuelos sucesivos (89 edificaciones; ver Tabla 1).

Respecto a la superficie que abarcan las cúpulas, no existen grandes diferencias entre los tres sistemas, aunque la cúpula auténtica parece ser una solución lógica para espacios más reducidos que la escalonada o la híbrida.

Más destacados son los datos en relación al tipo de planta, ya que el sistema auténtico, habitual en cúpulas de barro, tiene una mayor predilección por la forma cuadrada, aunque este hecho esté más relacionado por esa tendencia de las construcciones arcillosas por las plantas ortogonales, debido a la geometría ortogonal de sus principales elementos constructivos (tapial y adobe). De hecho, al indicar los tipos de cobertura sobre el mapa geológico, comprobamos que mientras que el sistema de aproximación de hiladas ha proliferado desde el páramo calizo hasta grandes áreas de la llanura, la bóveda auténtica se ha desarrollado principalmente en la arcilla de Tierra de Campos (Figura 4, superior). Resulta significativo que el sistema híbrido se ha dado con más frecuencia en la zona limítrofe entre ambas comarcas naturales, por lo que podemos concluir en este aspecto que esta tercera técnica ha podido resultar por la confluencia de las otras dos.

No podemos descartar que muchos de los casos de técnica abovedada híbrida hayan sido el resultado de reparaciones una vez el sistema original de aproximación de hiladas haya fallado en la coronación, pero tenemos buenos indicios para 

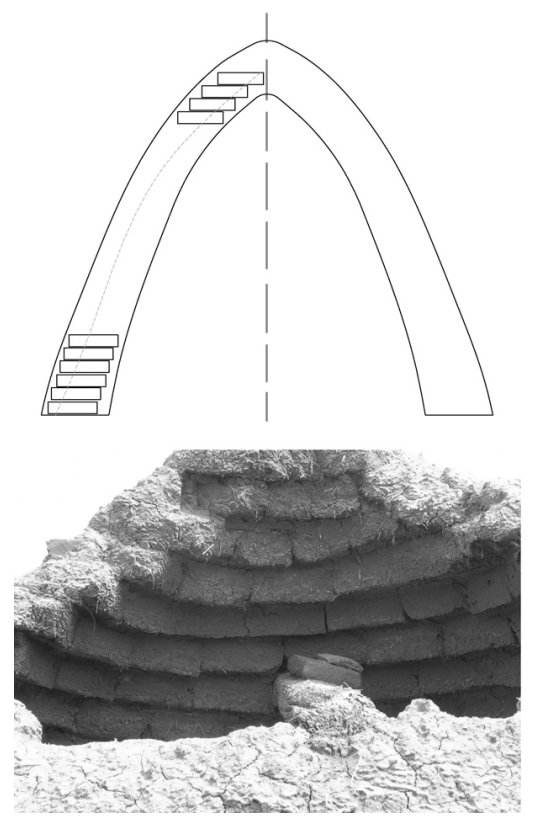

Figura 3. Esquemas gráficos e imágenes de ej
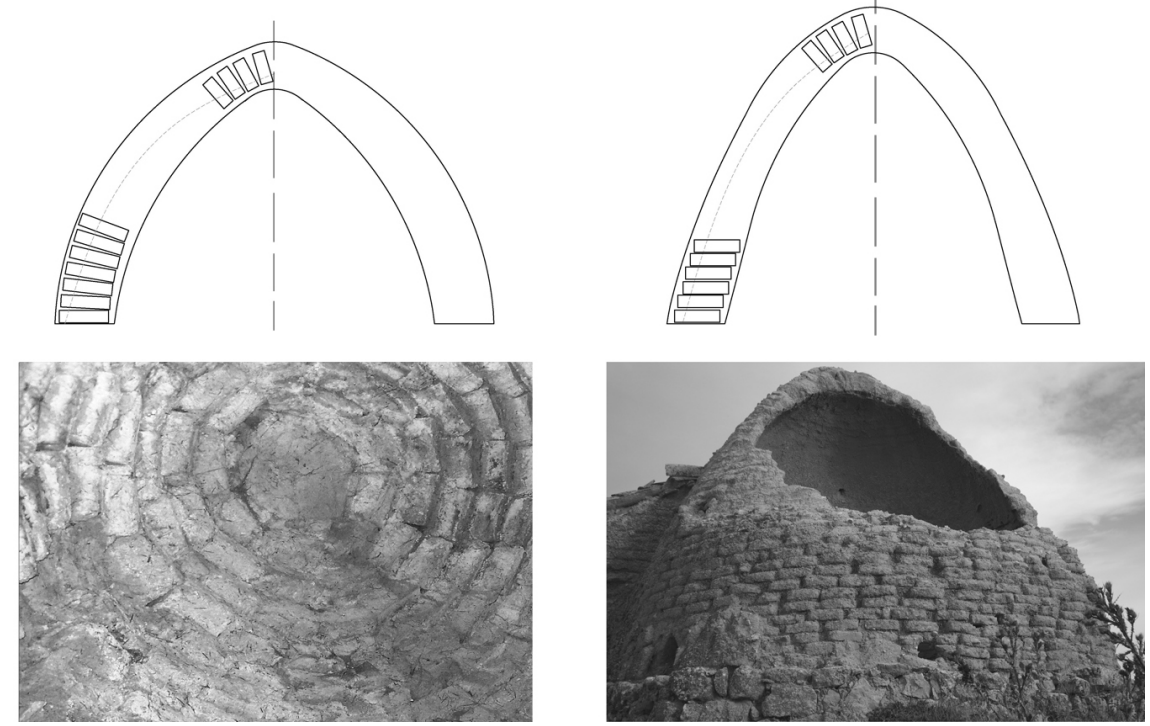

de piezas y sistema híbrido (elaboración propia).

Tabla 1. Tipos de sistemas abovedados según materiales en cubierta, zona geológica dominante, superficie construida de la edificación y tipo de planta (elaboración propia).

\begin{tabular}{|c|c|c|c|c|}
\hline TIPO DE SISTEMA & SISTEMA FALSO & \multicolumn{2}{|c|}{ SISTEMA AUTÉNTICO } & SISTEMA MIXTO \\
\hline TIPO DE FIGURA & CÚPULA & CÚPULA & BÓVEDA CORRIDA & CÚPULA \\
\hline N. ${ }^{\circ}$ de edificaciones Totales & 131 & 47 & 6 & 18 \\
\hline \multicolumn{5}{|l|}{ MATERIAL DE CUBIERTA } \\
\hline Arcilla (n. ${ }^{\circ}$ de casos) & 41 & 30 & o & 9 \\
\hline Piedra (n. ${ }^{\circ}$ de casos) & 89 & 1 & 6 & 2 \\
\hline Arcilla + Piedra (n. ${ }^{o}$ de casos) & 1 & 16 & o & 8 \\
\hline \multicolumn{5}{|l|}{ UBICACIÓN GEOLÓGICA } \\
\hline ÁREA BARRO (n. ${ }^{\circ}$ de casos) & 26 & 24 & o & 2 \\
\hline ÁREA MIXTA (n. ${ }^{\circ}$ de casos) & 49 & 22 & o & 16 \\
\hline ÁREA PIEDRA (n. ${ }^{\circ}$ de casos) & 56 & 1 & 6 & o \\
\hline \multicolumn{5}{|l|}{ TAMAÑO DE BÓVEDA } \\
\hline Superficie media construida $\left(\mathrm{m}^{2}\right)$ & 14,8 & 13 & - & 15,9 \\
\hline \multicolumn{5}{|c|}{ TIPO DE PLANTA DE LA EDIFICACIÓN } \\
\hline Cuadrada (n. ${ }^{\circ}$ de casos) & 79 & 35 & 2 & 10 \\
\hline Circular (n. ${ }^{\circ}$ de casos) & 45 & 8 & o & 8 \\
\hline Rectangular (n. ${ }^{\circ}$ de casos) & 4 & 1 & 3 & o \\
\hline OTRAS (n. ${ }^{\circ}$ de casos) & 3 & 3 & 1 & $\underline{\mathrm{O}}$ \\
\hline
\end{tabular}

concluir que se trata de una técnica evolucionada y más contemporánea que las otras dos.

\subsection{Tipología de las cúpulas, según sus materiales}

En lo que se refiere al material empleado de estas techumbres se ha podido encontrar una conversión entre los dos polos principales: además de las dos opciones naturales, arcilla (80 casos) y caliza (98 edificaciones), se ha encontrado una solución mixta de transición (con 25 ejemplares), donde la combinación entre adobes y piedras puede realizarse de diferentes maneras.

Según se comprueba en el plano geológico (Figura 4, inferior), las bóvedas pétreas sólo se mantienen en el páramo y en alguna localidad de la zona de transición, mientras que lo opuesto ocurre con las de arcilla. En esta misma franja limítrofe podemos encontrar las cubiertas abovedadas mixtas, resultado de la combinación de las otras dos. En este caso el mapa de apoyo ha servido para corroborar una de las ideas capitales de la arquitectura popular y de su buena economía de medios: construir con el material autóctono.

\subsubsection{Cúpulas de barro}

Las cúpulas de barro están levantadas con adobes y su disposición es tal que en el intradós siempre las aristas de las piezas están juntas. En su comienzo esta regla funciona bien con una pieza entera (normalmente de $40 \times 20 \times 8 \mathrm{~cm}$ en el centro castellano) ya que en las hiladas inferiores los anillos eran de diámetros importantes (3-4 m). Para conseguir la compresión tan sólo era necesario incluir en el extradós 

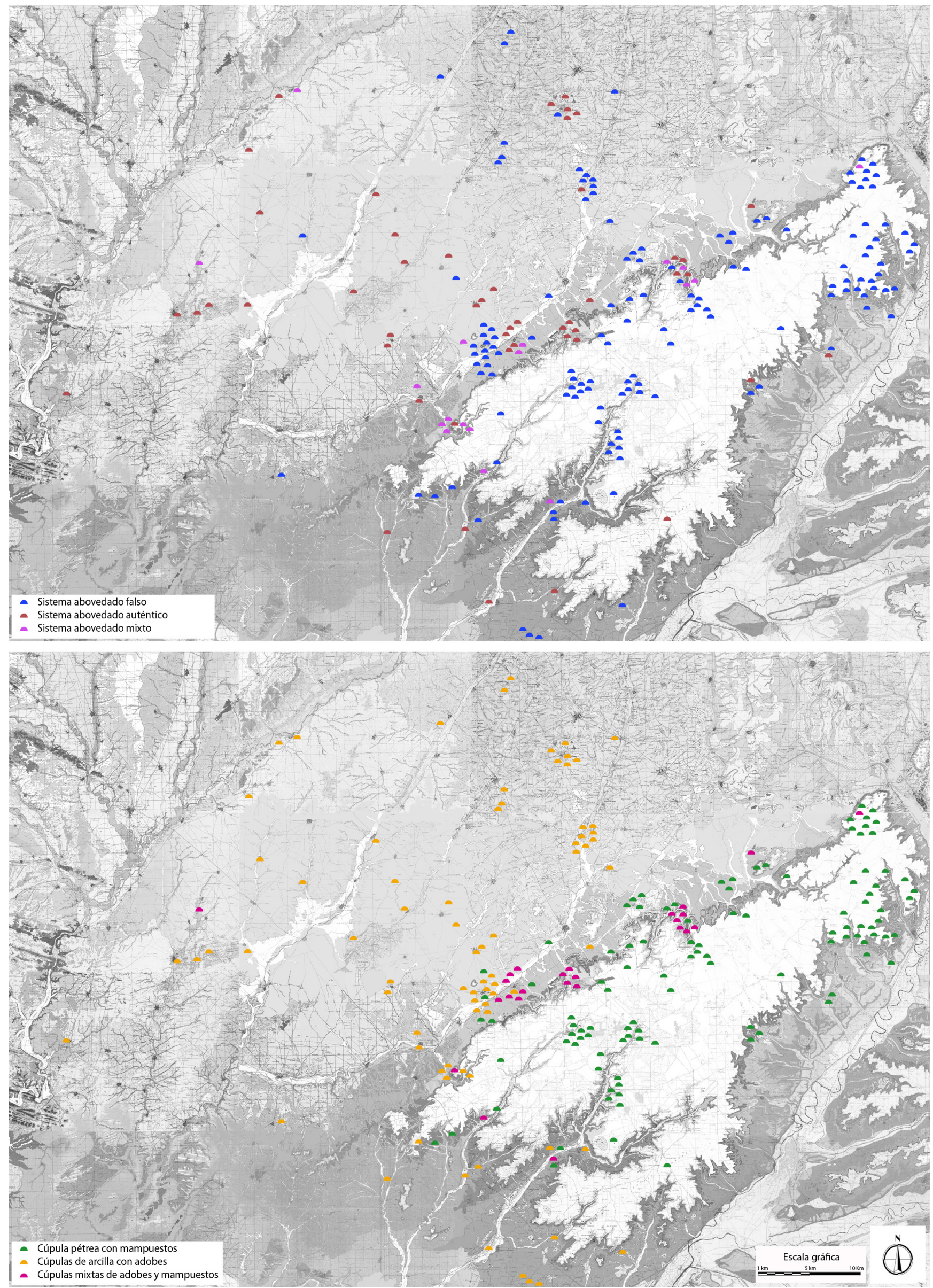

Figura 4. Mapas de tipos de cúpulas. Superior: tipos según el sistema de ejecución. Inferior: tipos según materiales (elaboración propia, sobre el mapa de la Figura 2). 
algunas pequeñas piedras o tejones² que hacían de cuñas, mezclándose con barro para agarrarse bien a los adobes (ver Figura 5, central-derecha).

Para la correcta colocación de las piezas los maestros locales se ayudaban normalmente de una cuerda, aunque los más experimentados podrían disponer de un cintrel o compás fijado en el centro de la esfera que además ayudaba a conseguir la inclinación adecuada en cada hilada si se trataba de una bóveda auténtica (15).

Según levanta la cúpula, hacia la mitad de su altura, en el extradós de los anillos el hueco entre adobes llega a ser muy espacioso. Para conseguir más homogeneidad en este cerramiento, y evitar tener más volumen de argamasa que de adobes, éstos podían cortarse en forma trapecial como si se tratara de la dovela de un arco (16).

Se conoce la existencia de gradillas especiales para dovelas de cúpulas, aunque estos moldes eran normalmente utilizados para bóvedas de hornos, que son más pequeñas y su forma es más semiesférica (17). No descartamos su empleo para chozos y casetas, pero parece más sencillo cortar el adobe una vez moldeado o incluso una vez seco, para lo cual se podía emplear un hacha.

Aunque había varias posibilidades, dependiendo de la maestría del albañil, uno de los métodos más sencillos era utilizar medios adobes cortados a pie de obra, y aprovechar las irregularidades del corte para trabar mejor en la unión entre piezas (Figura 5, inferior). Como se ha comprobado en la bóveda restaurada, este procedimiento también evita el deslizamiento de las piezas antes del secado del mortero de agarre, en las cúpulas auténticas, pues reduce a la mitad el peso del adobe ${ }^{3}$. De esta forma aparecían dos hojas de cerramiento que reducían el espacio de relleno a acuñar. Para conseguir la correcta unión entre pieles convenía utilizar un adobe entero cada 5 o 6 piezas que hiciera de perpiaño o llave. De este modo una vez finalizada la hilada interior, ésta servía de cimbra para la exterior. Para las últimas hiladas sí era conveniente usar piezas en forma de dovela y barro muy viscoso que seque con rapidez.

La disposición de adobes en planta no era diferente entre una técnica y otra. Para la de vuelos sucesivos unos anillos apoyan sobre otros y se añade algo de arcilla entre ambos para hacer un buen asiento. No obstante, en la bóveda auténtica este relleno se hacía con más volumen por el extradós, ya que así se conseguía mejor la inclinación del anillo hacia el centro de la esfera, e incluso también se podía utilizar alguna piedra para acuñar hiladas. Antes de la colocación de los adobes, éstos eran previamente regados o mojados levemente para mejorar su adherencia al mortero.

En ambos sistemas se revestía con barro por el exterior y a veces también por el interior. Este recubrimiento resulta importante para la rigidez estructural del conjunto, y para amoldar y alisar la bóveda evitando cualquier entrada y acumulación de agua entre anillos. En el caso del sistema escalonado el relleno de barro debe ser muy grueso para conseguir este objetivo. Finalmente, la bóveda era recubierta por un segundo revestimiento arcilloso con mucha paja llamado trullado, por su acabado alisado con llana o trulla, que ayuda a que las gotas resbalen con rapidez. A veces también se incrustaban tejas en las caras de vientos y lluvias dominantes (Figura 6).

\subsubsection{Cúpulas de piedra}

Las bóvedas pétreas son tan interesantes o más que las arcillosas. Su ejecución resulta un auténtico desafío dada la complejidad de lograr una forma tan regular con piezas sumamente orgánicas. En esta humilde arquitectura no hay cabida para la piedra perfectamente labrada, y tampoco existe mortero adherente, ya que su ejecución es en seco o a hueso (Figura 7). Sólo se ha visto en algún caso algo de barro que simplemente pudo servir para tapar las oquedades que había entre los mampuestos para mejorar el aislamiento.

Es por ello que su sistema de construcción es el de aproximación de hiladas, como no puede ser de otra forma utilizando piezas irregulares y sin pasta de agarre, que en un sistema auténtico rápidamente caerían antes de lograr la compresión anular.

Otra peculiaridad de estas bóvedas es que están compuestas normalmente por dos capas (Figura 8, central). La cáscara interior marca la correcta figura escalonada de la cúpula, mientras que la exterior es un complemento que hace de contrapeso de las lajas horizontales principales para evitar su posible vuelco. La capa del extradós no tiene por qué ser concéntrica al intradós: a menudo la sección de la cúpula es una figura parabólica cuyo espesor se reduce en la coronación. Aunque se han visto en la mayor parte de los casos nacer desde el mismo suelo o una base circular, las que se han apoyado sobre muros de planta cuadrada presentan una hoja exterior que tiende a la pirámide para adaptarse perfectamente y evacuar aguas más rápido (Figura 8 , superior).

En su ejecución se utilizan mampuestos de unos 8-12 cm de altura y unos 25-30 cm de longitud mínima (Figura 8, inferior) para apoyar la mayor parte de su superficie horizontal sobre la hilada inferior, y evitar el vuelco. Con una cuerda atada a un palo que hacía de eje se podía marcar la posición de cada elemento. Una ligera labra a base de golpes con alguna piqueta o martillo ayudaba a su correcta colocación, y una vez finalizada la hilada eran enripiados para conseguir la estabilidad.

En la zona Este del Páramo de los Torozos las lajas de piedra eran más planas y alargadas, y su ejecución resultaba más sencilla con este sistema.

Existe un gran número de cúpulas de piedra aun en buen estado. La durabilidad del material, en comparación a la tierra, ha permitido que se hayan localizado muchos más casos, a pesar que la superficie del área de estudio esté más dominada por la arcilla que por la caliza.

\subsubsection{Cúpulas mixtas}

Los casos de cúpulas mixtas, aunque no muy numerosos, crean un importante tipo abovedado considerado como una evolución creada a partir de las otras dos tendencias. Su ubicación en el plano geológico justifica su creación.

\footnotetext{
${ }^{2}$ Vocablo empleado en la zona para definir a trozos de tejas.

3 Su masa original es del orden de 10 kg, o más.
} 

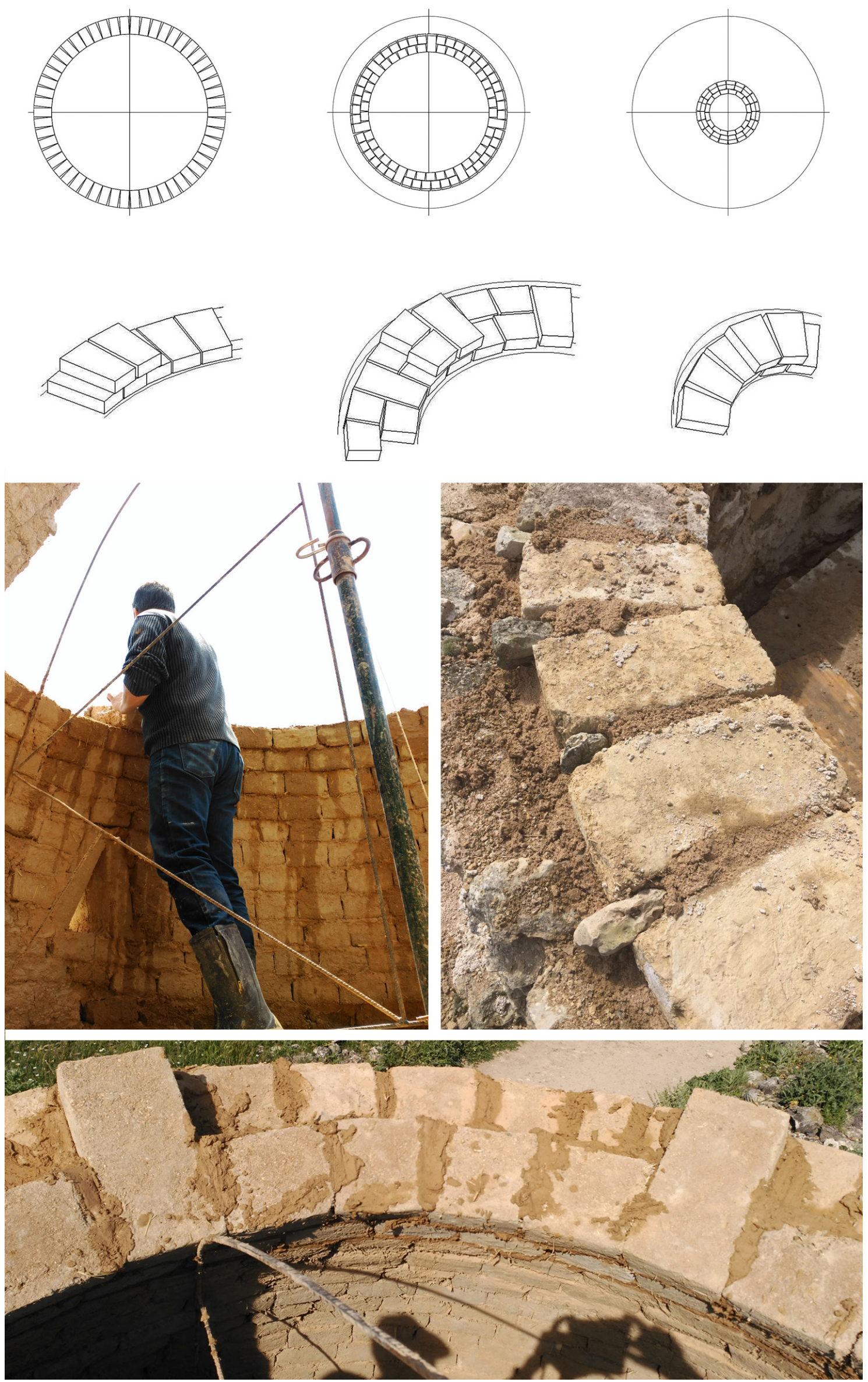

Figura 5. Superior: esquemas gráficos sobre hipótesis de colocación de adobes en cúpula en anillos iniciales, medios y finales. Central e inferior: procesos de reconstrucción de cúpula de adobes en un chozo de Urueña (Valladolid, abril-junio 2016) utilizando las teorías iniciales y ayudados por un cintrel (elaboración propia; fotos O. Abril). 

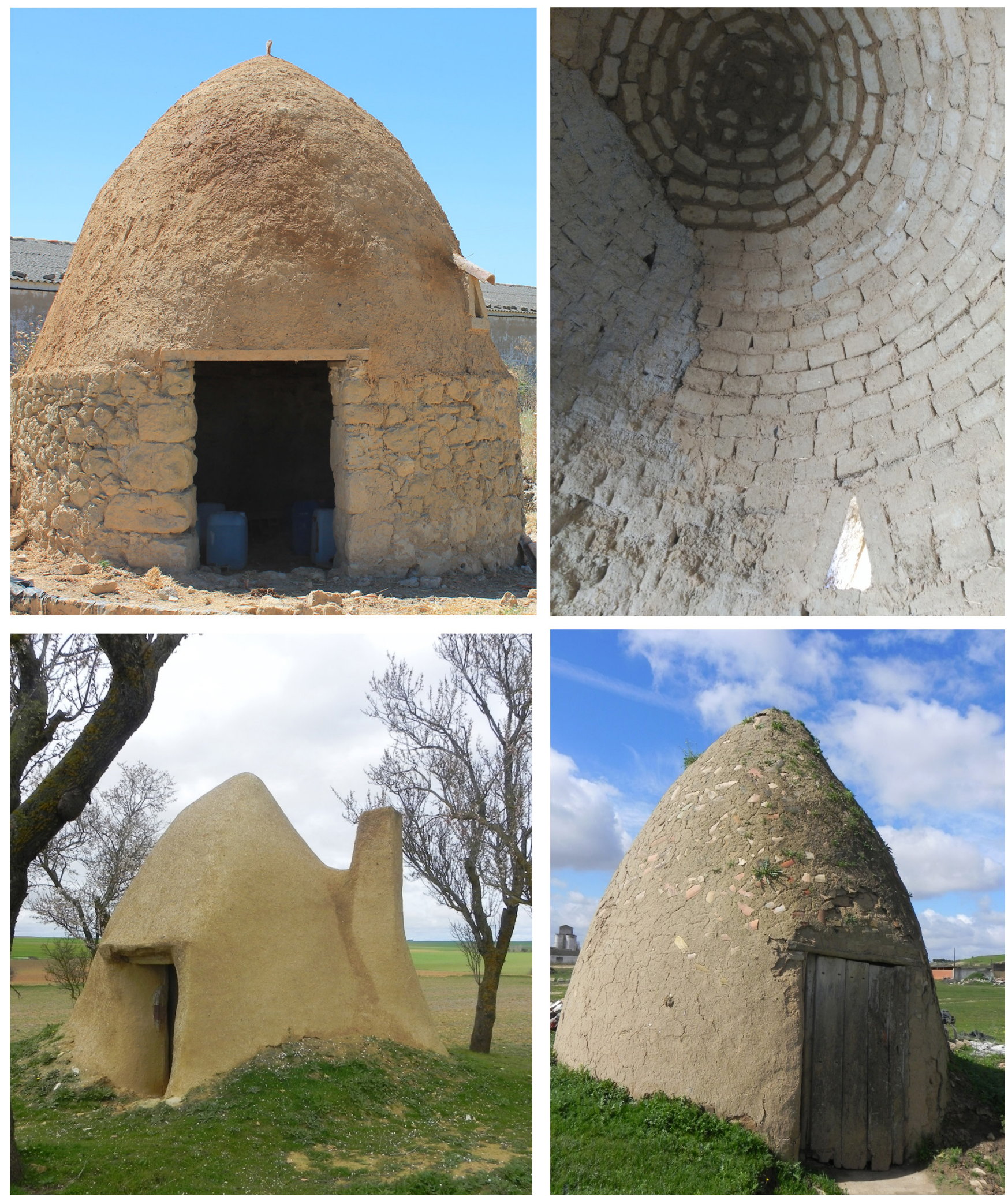

Figura 6. Superior: cúpula restaurada en el chozo de Urueña (Valladolid, abril-junio 2016). Inferior: guardaviñas en Ceinos de Campos (Valladolid, marzo 2013) con revestimiento reciente de barro y paja, y chozo de era en Torrecilla de la Abadesa (Valladolid, marzo 2013) con incrustación de tejas (fotos O. Abril).

Es posible que muchos de los casos de cúpulas mixtas sean rehabilitaciones, reformas o mejoras de cúpulas que no funcionaron originalmente, o se cayeran antes de terminarlas. En cualquier caso se han identificado tres subtipos de bóvedas donde en su recorrido existe la combinación de adobes y mampuestos calizos. Evidentemente en las partes pétreas hay dos capas y el sistema es el de aproximación de hiladas, mientras que en las zonas de arcilla podemos ver cúpula escalonada, auténtica o híbrida.

El primero de ellos, que designamos como mixto 1, es el más natural. Utiliza una hoja interior de adobes y otra exterior de 


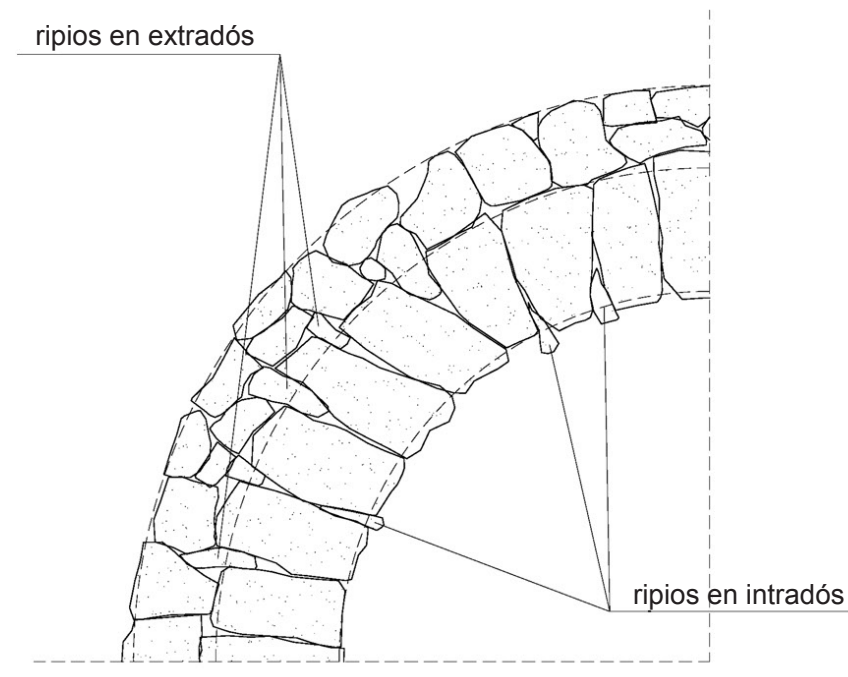

planta

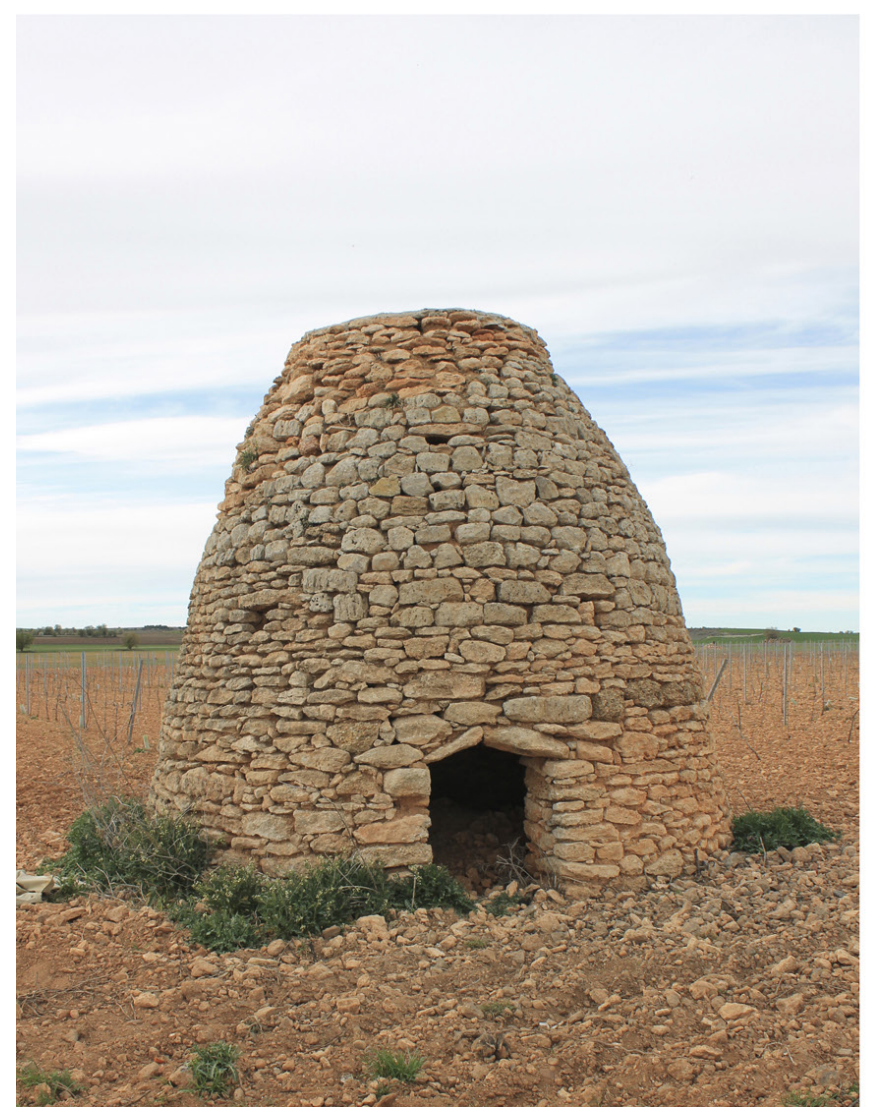

Figura 7. Superior: esquemas gráficos de la colocación de mampuestos para la creación de cúpulas de piedra. Inferior: chozo en Corcos del Valle (Valladolid, abril 2015) (elaboración propia, fotos O. Abril).

mampuestos (Figuras 9-1 y 10, superior). La capa pétrea no es un simple revestimiento, sino que configura un auténtico caparazón calizo. La solución es muy interesante, ya que cuenta con la mayor facilidad para la formación de la bóveda con adobes, y aprovecha la protección de la intemperie que proporciona la costra de piedra, que evita un mayor desgaste por el hostigo.

En el segundo tipo, designado como mixto 2, la cúpula nace sólo con piedra hasta llegar a una altura donde la figura no ha
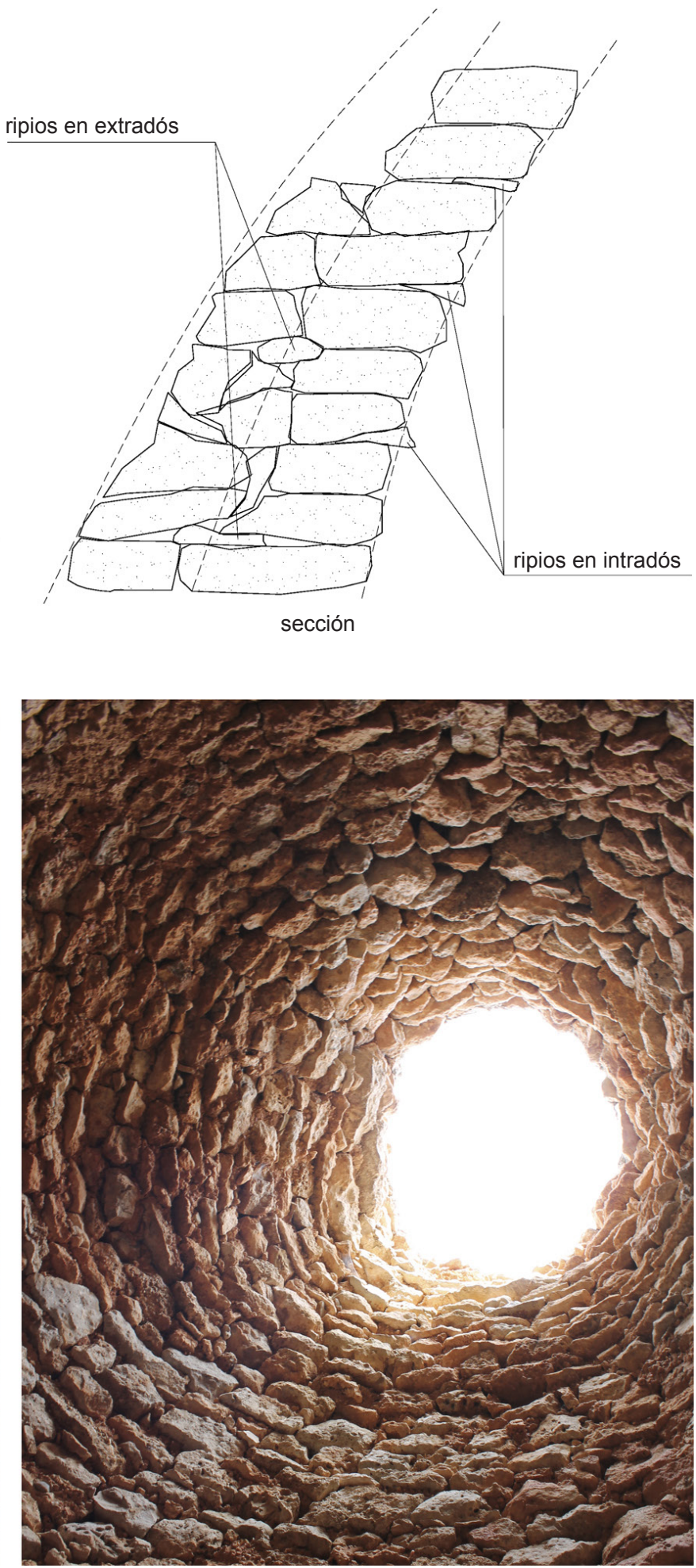

empezado todavía a cerrarse profundamente. Como la culminación de la cubierta resulta más complicada con el sistema de vuelos sucesivos, se sustituyen los mampuestos de la coronación por adobes, elementos más útiles para esta acción ya sea formando una cúpula auténtica o falsa (Figuras 9-2 y 10, medio).

El último tipo, mixto 3, es una evolución de los otros dos anteriores. Es decir, existe al principio un nacimiento de la cúpula con mampuestos escalonados, y cuando en el cierre de 

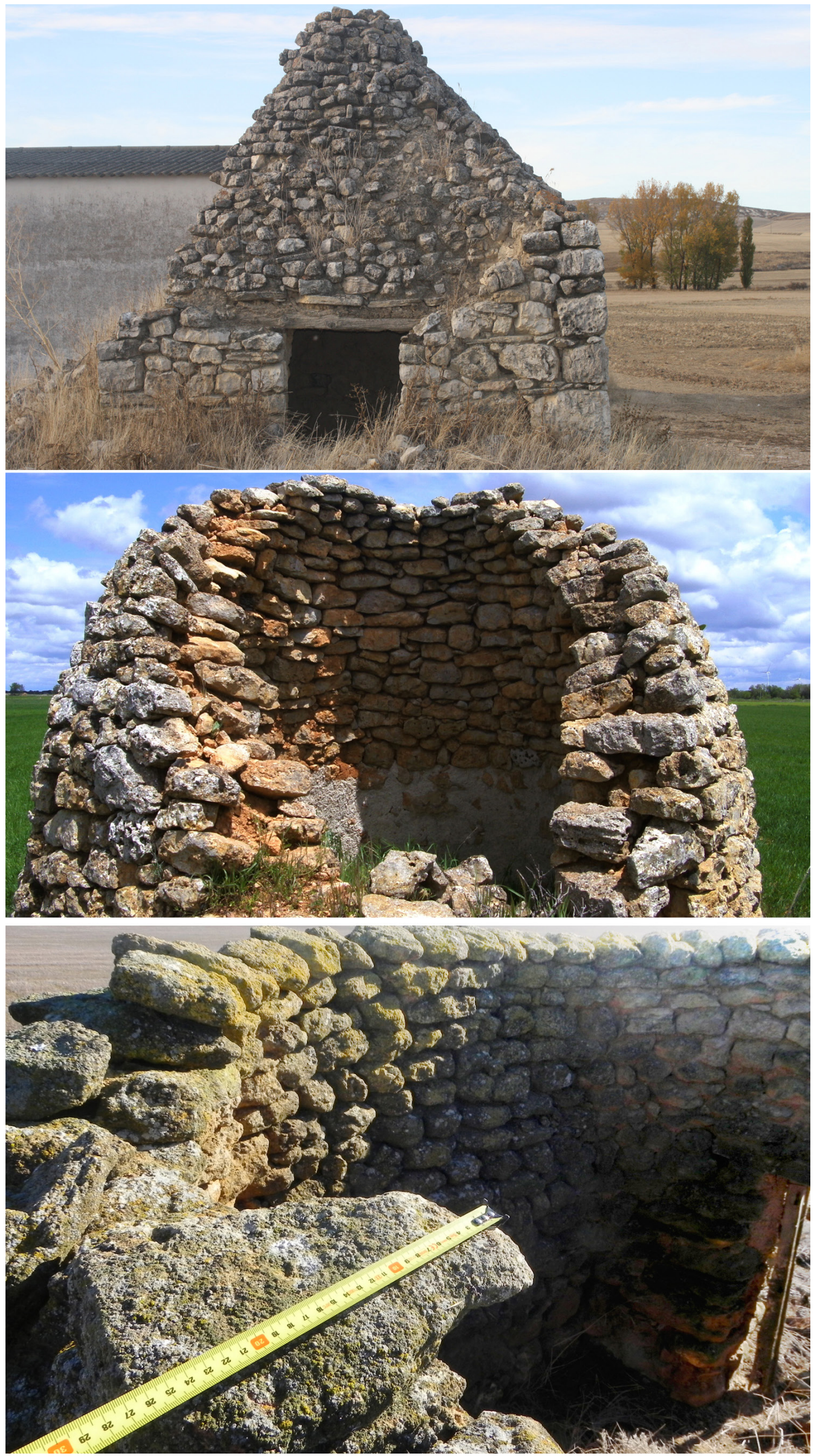

Figura 8. Chozos de piedra en Villasexmir (Valladolid, octubre 2011), Villalba de los Alcores (Valladolid, mayo 2013) y Tordehumos (Valladolid, diciembre 2013) (fotos O. Abril). 


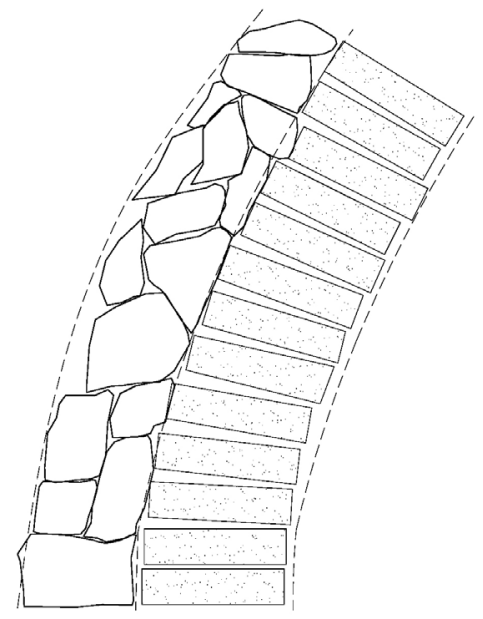

Mixta 1

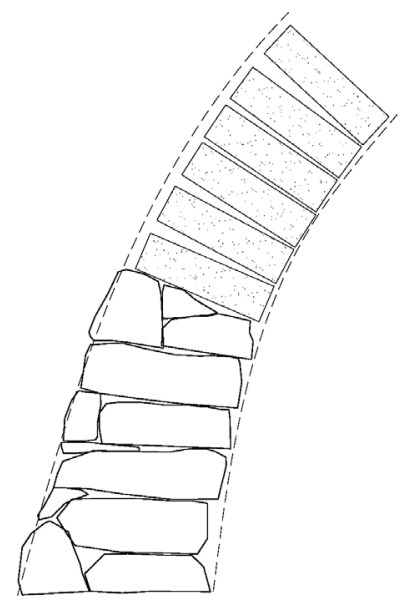

Mixta 2

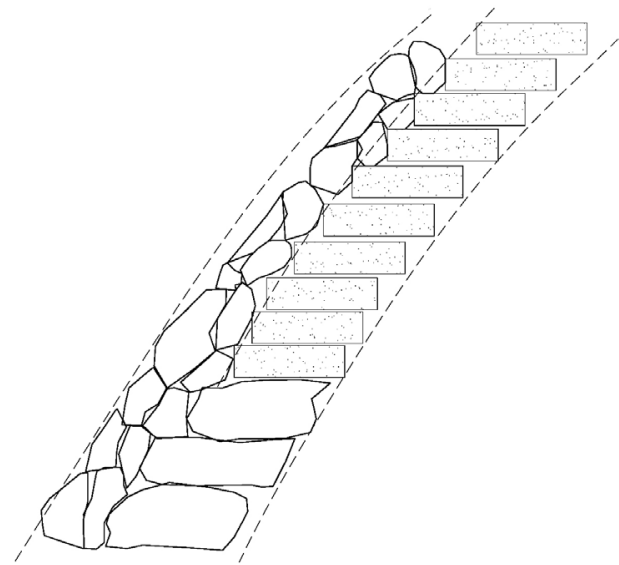

Mixta 3

Figura 9. Esquemas gráficos de los subtipos de cúpula mixta (elaboración propia).

la cúpula la compresión anular se hace difícil con estas lajas, aparece el adobe para hacer más sencilla la última parte de la bóveda. Pero esta capa es sólo interior, pues luego una segunda capa pétrea aparece como continuación de la exterior que ya se había comenzado en piedra caliza. Como en la culminación la cúpula se va aligerando, es frecuente la ejecución de esta parte con medios adobes. Así permite que las piedras que lo cubren apoyen bien sobre las piezas inferiores (Figuras 9-3 y 10 , inferior).

Dada la poca permeabilidad que existía en la superficie pétrea, era frecuente que estas cubiertas mixtas recibieran sobre esta capa exterior un buen revestimiento para proteger mejor al conjunto. Normalmente el sistema era el mismo que el de las cubiertas de arcilla: barro con mucha paja.

Un problema de esta estrategia mixturada es la falta de agarre entre las dos pieles. El barro no acaba de ser un buen ligante con la piedra, sobre todo cuando el agua penetra con fuerza entre las oquedades de las piezas pétreas hasta llegar a la capa arcillosa. En el momento en que ésta se humedece, se hace más inestable y los mampuestos por su peso empiezan a deslizar hasta que se llegan a caer. Tan sólo unos pocos ejemplos de estas bóvedas nos han llegado en buen estado a nuestros días.

\section{DISCUSIÓN DE RESULTADOS. CONCLUSIONES}

Se han extraído una serie de conclusiones a partir de los resultados obtenidos, algunas ya adelantadas en el presente escrito, que a continuación se enumeran:

\section{a) Documentación publicada}

Aunque los grandes autores de la arquitectura popular no han centrado sus trabajos especialmente en las construcciones secundarias, si ha existido un interés en las soluciones abovedadas, que ha surgido paralelamente a la desaparición de las mimas. No obstante, no existen trabajos que examinen en profundidad el procedimiento constructivo de estas bóvedas más allá de la explicación conceptual del sistema de ejecución, sin dar datos concretos como medidas, inclinaciones, etc. Por tanto, se considera necesario seguir tratando de documentar en plenitud estos elementos efímeros.

\section{b) Método de trabajo}

Los procedimientos empleados han sido sencillos en correspondencia a esta humilde arquitectura, primando el trabajo de campo y la ordenación de sus resultados para sacar conclusiones con la mayor objetividad posible. Por otro lado, la recuperación de una cúpula de adobes ha supuesto uno de los experimentos más útiles para poder comprobar algunas de las hipótesis supuestas en relación al proceso de ejecución, como la forma de colocación de los adobes, la división de pieles, el revestimiento de protección, etc.

\section{c) Tipos de sistemas abovedados}

Muchos autores sólo identifican estas construcciones con la cúpula de vuelos sucesivos por la elementalidad de su proceso de ejecución, y unos pocos han sabido identificar el sistema auténtico en sus cubiertas, pero en el trabajo de campo se ha podido comprobar la existencia de un sistema híbrido, hasta ahora desconocido en la bibliografía especializada de la arquitectura popular, que se debe a un interesante efecto de transmisión de la herencia cultural entre pueblos. El mapa de la zona de estudio corrobora tal consideración.

\section{d) Empleo de los materiales}

Aunque de antemano se intuía que sobre el sustrato geológico las cúpulas de barro iban a aparecer sobre la región de Tierra de Campos (arcillosa) y las de piedra sobre los Montes Torozos (calcáreos), se ha comprobado esta realidad y, además, se ha identificado un tipo de bóvedas mixtas situado mayoritariamente en la franja limítrofe entre ambas comarcas naturales. De esta manera no sólo se confirma otro de los condicionantes de la arquitectura popular, su apego al material inmediato, sino que se ha desvelado la creación de una arquitectura singular y exclusiva de la arquitectura rural peninsular ubicada en el centro de la Vieja Castilla, y que hasta el momento había estado oculta a la ciencia. Este hecho queda demostrado a partir del mapa peninsular de cúpulas (Figura 1) elaborado por los investigadores valencianos Vegas, Mileto y Cristini, el cual ha sido comparado y ampliado 

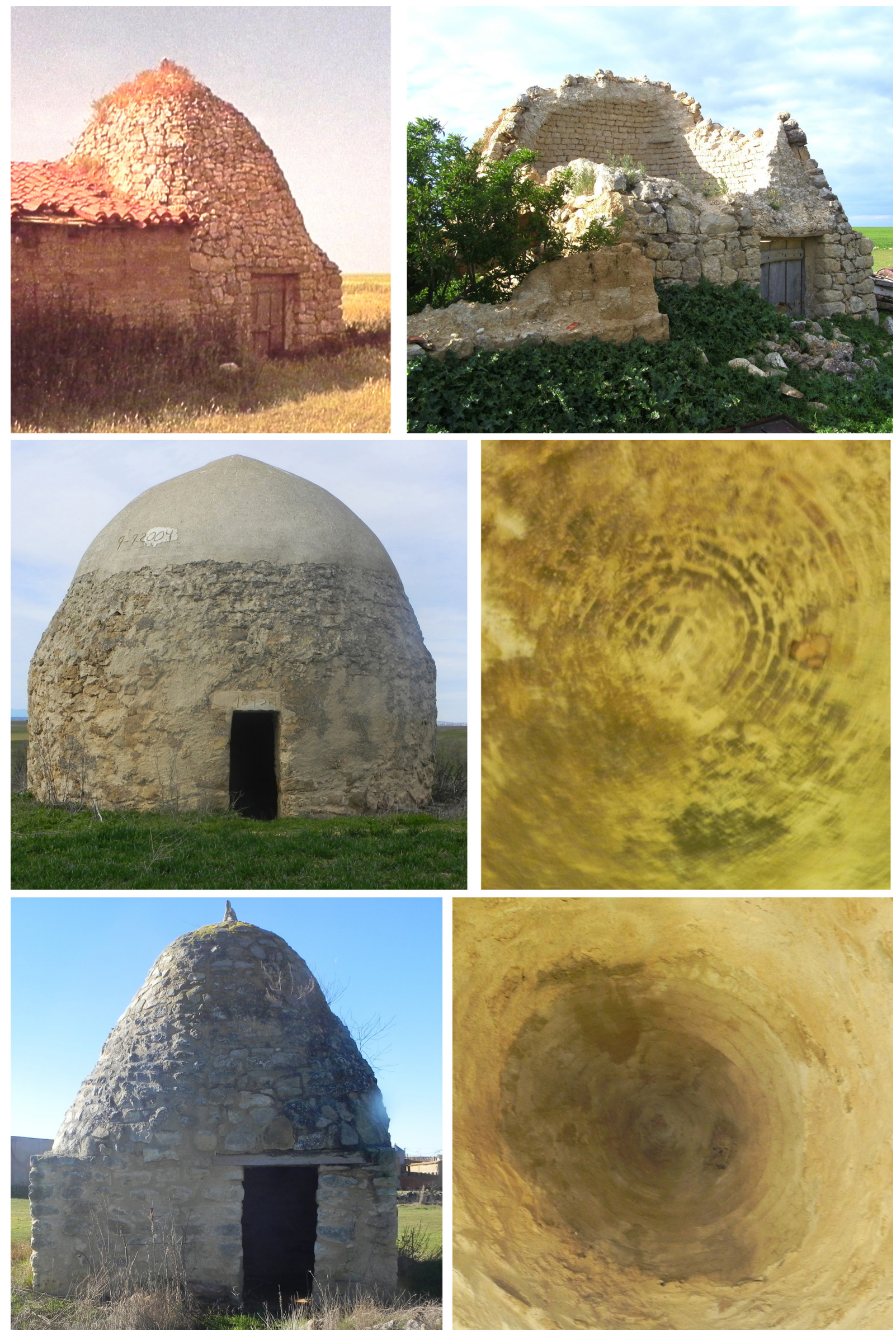

Figura 10. Tipos de cúpula mixta. Superior: chozo de cúpula mixta tipo 1 en Autilla del Pino (Palencia) en 1989 (18) y en mayo 2013. Central: bóveda mixta tipo 2 en una caseta en Vidayanes (Zamora, febrero 2013). Inferior: chozo con cúpula mixta tipo 3 en Villasexmir (Valladolid, enero 2014) (elaboración propia). 


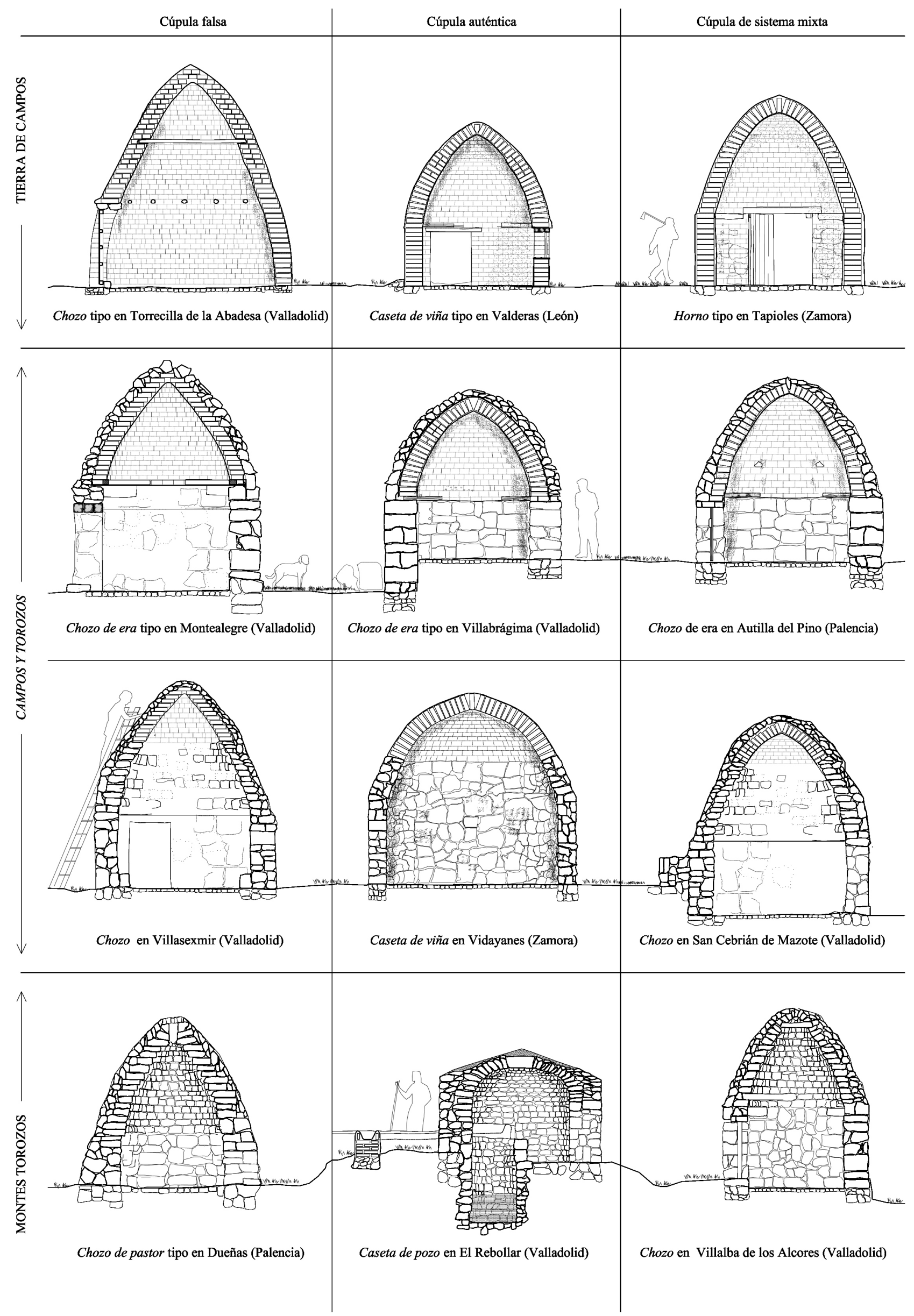

Figura 11. Esquema tipológico de cubiertas abovedas en función del sistema y del material (elaboración propia). 
con el mapa geológico fruto de las expediciones realizadas en nuestra investigación.

No obstante, si bien esta arquitectura vernácula se considera un elemento en continua evolución, no podemos decir que el resultado de este invento mixturado ideado por los constructores locales con la intención de mejorar sus obras sea óptimo, a la vista de los escasos ejemplos que en mal estado se han encontrado.

e) Proceso de ejecución de cúpulas

Aunque escasas, las explicaciones de ciertos autores nos han servido para el conocimiento constructivo básico de las cúpulas tratadas. No obstante, era necesaria una descripción más exhaustiva para comprender su correcta ejecución. A través de la intervención sobre el caso expuesto se ha comprobado el desarrollo de las diferentes fases de construcción con im- portante grado de detalle. Es por ello que se concluye que al menos una parte del conocimiento arquitectónico sobre estas cúpulas ha sido recuperado y documentado.

f) Puesta en valor de techumbre abovedadas

Tanto por los materiales como por su escala, la integración de estos elementos en el paisaje es total. Además, la importancia que tuvieron en las actividades económicas tradicionales de la zona los dota de un notable valor evocativo y cultural. Finalmente, dado que tras observar sus características arquitectónicas es posible agrupar y clasificar y agrupar tipológicamente los 202 casos analizados (Figura 11), se concluye que las cúpulas de la arquitectura rural del centro de Castilla y León configuran un conjunto de interés patrimonial, digno de protegerse y conservarse según las técnicas y las reglas tradicionales, algunas ya explicadas en el presente estudio.

\section{REFERENCIAS}

(1) Olcese Segarra, M. (1993). Arquitecturas de tierra: Tapial y adobe, p. 155, Valladolid: Colegio Oficial de Arquitectos en Valladolid.

(2) Löbbecke, R. (2012). Kragkuppelbauten, Köln: Walter Köning.

(3) Flores, C. (1974). Arquitectura popular española, tomo 3. Meseta norte, Sistemas Central e Ibérico y Meseta sur y Extremadura, Madrid: Aguilar.

(4) Feduchi, L. (1974). Itinerarios de arquitectura popular española, tomo 1. La meseta septentrional, Barcelona: Blume.

(5) Benito Martín, F., y Hiernaux González, J. L. (1998). La arquitectura tradicional de Castilla y León, Valladolid: Junta de Castilla y León, Consejería de Medio Ambiente y Ordenación del Territorio.

(6) Roldán Morales, F. P. (1996). Arquitectura popular de la provincia de Valladolid, p. 225, Valladolid: Diputación Provincial de Valladolid.

(7) Vegas. F., Mileto, C., Cristini, V. (2010). Corbelling domes and bridges in Spain and Portugal: A comparative study. En Arch'1o, 6 Intenational Conference on Arch Bridges (p. 81). Fujian (China): College of Civil Engineering of Fuzhou.

(8) Carricajo Carbajo, C. (1995). Construcciones secundarias, p. 78, Valladolid: Castilla.

(9) González Garrido, J. (1941). La Tierra de Campos: Región natural, p. 234, Valladolid: Ámbito.

(10) González Garrido, J. (1955). Los Montes de Torozos: comarca natural, p. 286, Valladolid: Falange Española Tradicionalista y de las J.O.N.S.

(11) Ministerio de Economía y Competitividad (2013). Servicios de mapas. Instituto Geológico y Minero de España. http:// mapas.igme.es/Servicios/.

(12) Martín Criado, A. (1992). Construcciones de falsa cúpula en el Valle del Duero. Revista de Dialectología y Tradiciones Populares, 47: 303-357.

(13) Carricajo Carbajo, C. (2010). 5o + 1 construcciones vernáculas en la provincia de Valladolid, p. 173, Valladolid: Diputación Provincial de Valladolid.

(14) Heyman, J. (1999). El esqueleto de piedra: Mecánica de la arquitectura de fábrica, p. 49, Madrid: Centro de Estudios Históricos de Obras Públicas y Urbanismo.

(15) Esteve Armengol, J. (1986). Estructuras abovedadas de tierra. En Centro de Investigación de Técnicas y Materiales de Construcción Experimentales, I Encuentro de Trabajo sobre la Tierra como Material de Construcción (p. 87). Soria: Diputación Provincial de Soria-Inter-Acción.

(16) Carricajo Carbajo, C. (2010). 5o + 1 construcciones vernáculas en la provincia de Valladolid, p. 169, Valladolid: Diputación Provincial de Valladolid.

(17) Sánchez Sanz, M. E. (1977). El barro en la construcción. Narria: Estudios de Artes y Costumbres Populares, 8: 33.

(18) Alcalde Crespo, G. (1989). Palencia, barro, madera y piedra, p. 211, Palencia: Merino. 